\title{
Influence of Vanadium-Chromium Carbide on the Microstructure of Reinforced FeCrV15 Hardfacing during Laser Cladding Deposit
}

Basiru Philip Aramide ( $\square$ abashiruphilip@gmail.com )

Tshwane University of Technology SA

\section{Sisa Pityana}

Centre for Scientific Innovation and Research SA

Tamba Jamiru

Tshwane University of Technology SA

Patricia Popoola

Tshwane University of Technology SA

\section{Rotimi Sadiku}

Tshwane University of Technology SA

\section{Research Article}

Keywords: Laser cladding, hard coatings, microstructural modification

Posted Date: June 21st, 2021

DOl: https://doi.org/10.21203/rs.3.rs-636243/v1

License: (c) (i) This work is licensed under a Creative Commons Attribution 4.0 International License. Read Full License

Version of Record: A version of this preprint was published at Journal of Materials Engineering and Performance on August 23rd, 2021. See the published version at https://doi.org/10.1007/s11665-02106153-w. 


\section{Abstract}

The increasing manufacturing technologies is a crucial aspect of industrialization. Laser additive manufacturing is the process of manufacturing using laser (heat) technology to manufacture component from scratch and or strengthening and modification of surfaces that are subject to abrasion. The combination of both Chromium Carbide $(\mathrm{CrC})$ and Vanadium Carbide reinforced iron based hard facings have gotten progressively significant in enhancing the corrosion and wear resistance of tool subject to adverse abrasive and impact conditions. This study investigates the effect of vanadium-chromium carbide on the microstructure of the clad with respect to its laser processing parameters.

\section{Introduction}

The increasing manufacturing technologies are a crucial aspect of industrialization. This is because the production of components and spare parts for industries such as aerospace, agriculture, nuclear, energy, and automobile are achieved through them. These technologies may be classified into conventional subtractive or shaping manufacturing, and the more recent ones like additive manufacturing (AM). AM is the creation of parts by adding endless layers of the material segment through cutting-edge fabricating innovation with a 3D model design, which is sectioned into numerous layers, this enables the creation of complex components without momentary advances. This technology is at present a preferred option in contrast to existing subtractive manufacturing processes. This is attributed to its numerous potential benefits, for example, its capacity to produce complex components utilizing materials that are difficult to machine. Laser additive manufacturing is the process of manufacturing using laser (heat) technology to manufacture components from scratch (i.e., LENS, SLM, etc.), and, or strengthening and modification of surfaces that are subject to abrasion (i.e., laser transformation hardening, laser cladding, etc.).

Laser cladding, as surface strengthening, modification, and repairing technology, has benefits like low heat affected zone (HAZ), minor stress deformation, very low and minimal dilution ratio, and improved metallurgical adhesion of the clad to the substrate. The minimal dilution ratio of laser cladding gives an advantage over other methods such as gas metal arc welding (GMAW), submerged arc welding (SAW), etc. It has great application possibilities in enhancing the corrosion resistance and wear resistance of materials (Aramide et al., 2020). This makes it to be increasingly applied in surface and manufacturing engineering. A numerous variation of materials can be deposited on a substrate through laser cladding by powder injection to form a layer with thicknesses varying between 0.05 to $2 \mathrm{~mm}$ and widths as thin as 0.4 mm (Toyserkani et al., 2004).

Iron-based alloy (mild steel and carbon steel) are commonly used for the manufacturing of ground engaging components of agricultural and mining tools, but with poor corrosion and wear resistance when put to its working condition, hence the incessant replacement of such tools. There is a need to improve the wear and corrosion resistance of steel used for such implements, and it is the key to expanding their durability in applications. The combination of both Chromium Carbide $(\mathrm{CrC})$ and Vanadium Carbide reinforced iron-based hard facings have gotten progressively significant in enhancing the corrosion and 
wear resistance of tools subject to adverse abrasive and impact conditions. The precipitate of primary VCs, eutectic VCs, and Chromium-rich eutectic carbides stand as resistance against the infiltrating grating medium (Bouaifi et al., 1997). VCs and CrCs as reinforcements improve grain refinement of iron-based alloy, resulting in increasing the toughness, which has an improvement in wear resistance (Lampman and Peters, 1981). The aim of this work is to investigate the impact the precipitation of Vanadium-Chromium Carbide has on the microstructure and hardness of reinforced clad on mild steel.

\section{Materials And Methods}

\subsection{Laser Processing Equipment and Materials}

The cladding of the FeCrV15 high carbon ferrochrome powder was methodically done layer by layer on SAE 1020 steel baseplate at the Council for Scientific and Industrial Research, Pretoria South Africa. Table 1 shows the composition by weight of the high carbon ferrochrome powder FeCrV15 used in the experiment. The powder was supplied commercially by WearTech of South Africa, with purity well above $99 \%$, which was utilized without modification as received. Table 2 displays the samples and there processing parameters, the combinations of these parameters utilized for the cladding was determined through optimization (Bayer, 2008).

Table 1

The composition by weight of High carbon ferrochrome FeCrV15 powder

\begin{tabular}{|llllllll|}
\hline Element & C & Mo & Fe & Mn & Cr & Si & V \\
\hline Weight\% & 4.5 & 1.3 & Balance & 1.1 & 14.0 & 1.1 & 15.4 \\
\hline
\end{tabular}

The deposition was made on the substrate after it was sandblasted to enhance the absorptivity of the laser light to reduce the reflection of the laser beam; this also increases the adhesion between the alloy and the baseplate. The surface was later cleaned and air dried to remove contamination before the laser cladding deposition process. The experiment was completed utilizing a $3 \mathrm{~kW}$ Continuous Wave(CW) Rofin Sinar Nd:YAG laser system represented in Fig. 1.

\section{Methods}

Table 2

Laser processing parameters

\begin{tabular}{|llll|}
\hline Samples & Laser power $(\mathrm{W})$ & Scanning speed $(\mathrm{m} / \mathrm{s})$ & Powder feed-rate $(\mathrm{m} / \mathbf{s})$ \\
\hline A & 1200 & 8 & 5 \\
\hline B & 1200 & 10 & 5 \\
\hline C & 800 & 8 & 5 \\
\hline
\end{tabular}

\subsection{Metallographic Investigation and Image Processing}


The samples were sectioned, grounded, and polished for metallographic examination. Both dilution rate A and microstructure was of interest. The carbide precipitation in the microstructure were observed by Optical microscope(OPM) and Scanning electron microscope(SEM). The samples were etched with modified Fry's Reagent $\left(150 \mathrm{ml} \mathrm{H}_{2} \mathrm{O}, 50 \mathrm{ml} \mathrm{HCl}, 25 \mathrm{ml} \mathrm{HNO}_{3}\right.$, and $1 \mathrm{~g} \mathrm{CuCl}_{2}$ ) solution.

Scanning electron microscopic equipped with electron dispersive Spectron(SEM/EDS) was used to analyze the samples. The elemental compositions were determined by the EDS at a voltage of $20 \mathrm{kV}$.

Vickers microhardness tester, with a load of $2.94 \mathrm{~N}$ and a dwelling time of $10 \mathrm{~s}$, was used to take the hardness of the coatings beginning at the top surface. The reading was taken every $0.2 \mathrm{~mm}$ until the core of the substrate is reached.

\section{Results}

From the SEM micrograph, see Figs. 3a and $b$, 'dark coloration could be allotted to light elements and bright coloration to heavy elements'(Günther and Bergmann, 2020). The dark precipitates signify Vanadium carbides(VCs), the whitish eutectic lamellar phase signifies Cr-rich carbide and the dark gray portion martensite and austenite phase. However, in the images from the optical microscope vanadium and chromium carbides are identified as white precipitates, Figs. 4c, and d. This is in agreement with Günther and Bergmann (Günther and Bergmann, 2020),

Primarily, the vanadium carbide is indicated by the dark star-flower-like structure(Ma et al., 2010) and fishbone or rod-like solidification( Fig. 3c and d) in the micrograph, position 2 and 3. Furthermore, a precipitate of dark, greyish, and round shapes dispersed all over the microstructure is obvious, these indicate eutectic vanadium carbides, position 1 . While the combination of eutectic vanadium-chromium carbide stands out as whitish spots (in Fig. 3d but greyish dark sport in 3c) indicating martensite all aver the microstructure. The greyish portion not affected by the etchant (position 4) is regarded as retained austenite. A moderately darker phase could be identified, separate from the greyish retained austenite with a portrait of fine eutectic lamellar microstructure at position 5 . This is presumed to be chromium-rich carbide.

Additional investigations were carried out by the means of SEM-EDS analysis for further confirmation of the above assertion. The elemental composition as detect in the phases are listed in Table 3 below. Positions 2 and 3 have the highest vanadium content of $\otimes 53$ and $\otimes 60$ wt. \% respectively. This further corroborates the precipitation of Vanadium carbide. The coloration of the eutectic vanadium carbide is relatively close to that of the primary VCs; however, the elements stand out like engraved balls on the microstructure with a V-content of $\otimes 14$ wt. \%, see Table 3 (Position 1). The Eds analysis for position 5 confirmed the assumption of chromium-rich carbide with a Cr-content of $\nabla 21 \mathrm{wt}$. \%. 
Table 3

EDX measurement of the examined position

\section{Element Elemental Component of the Examined Positions (wt. \%)}

\begin{tabular}{|llllll|}
\hline & $\begin{array}{l}\text { Position 1 } \\
\text { Eutectic } \\
\text { Vanadium } \\
\text { Carbide }\end{array}$ & $\begin{array}{l}\text { Position 2 } \\
\text { Vanadium }\end{array}$ & $\begin{array}{l}\text { Position 3 } \\
\text { Vanadium } \\
\text { Carbide }\end{array}$ & $\begin{array}{l}\text { Position 4 Iron-rich } \\
\text { Matrix(Martensite and } \\
\text { Retained Austenite) }\end{array}$ & $\begin{array}{l}\text { Position 5 } \\
\text { Chromium Rich } \\
\text { Eutectic Carbide }\end{array}$ \\
\hline C K & 9.32 & 22.23 & 17.67 & 4.49 & 5.72 \\
\hline S K & 0.00 & 0.00 & 0.00 & 0.00 & 0.00 \\
\hline V K & 0.90 & 0.56 & 0.35 & 1.00 & 0.65 \\
\hline Cr K & 13.53 & 53.05 & 60.11 & 4.02 & 5.52 \\
\hline Fe K & 65.86 & 5.94 & 7.99 & 9.45 & 20.80 \\
\hline Mn K & 0.94 & 17.04 & 11.98 & 79.54 & 67.03 \\
\hline Mo K & 0.78 & 0.16 & 0.66 & 0.81 & 0.55 \\
\hline
\end{tabular}

\subsection{Microstructural characteristics of the clad 3.1.1 Effect of clad depth on microstructure}

The pattern of the phase arrangement changes as one moves away from the substrate into the clad layer. Close to the substrate, $\nabla 200$ to $400 \mu \mathrm{m}$ into the clad, there is the formation of the eutectic carbides(VCs \& Cr-rich) were observed with dark martensitic phases scatted all over the microstructure, see Fig. 4a. At about $500 \mu \mathrm{m}$ into the clad, the precipitation and agglomeration of primary VCs began with an average diameter of about $0.69 \mu \mathrm{m}$ with dark martensitic phase encapsulating each one(these were identified as eutectic VCs by Günther and Bergmann, 2020) and eutectic VCs and Cr-rich carbide were observed, see Fig. 4b. Eutectic VCs continues to agglomerate to form star-like precipitates of primary VCs with an average diameter of $2.55 \mu \mathrm{m}$ between 650 to $900 \mu \mathrm{m}$ into the clad, see Figs. 4c \& d respectively. From the OPM images, it was difficult to distinguish between the Cr-rich carbides and retained austenite phases up to about $750 \mu \mathrm{m}$ away from the substrate, see Figs. $4 \mathrm{a}, \mathrm{b}$, and c. However, as you move farther into the clad, they were clearly distinguishable, see Figs. $4 d$, e, \& f.

Furthermore, the eutectic VCs were observed to reduce as precipitation of primary VCs increases, this is proportionate to the height of the clad (distance away from the substrate).

\subsubsection{Effect of laser power and scanning speed(temperature) on microstructure}


The images in Fig. 5 indicate the influence of scanning speed on solidification and precipitation of phases formed in the microstructure of the clad. The micrographs are of two samples, A \& B, both processed at $1.2 \mathrm{~kW}$ laser power, and $5 \mathrm{~m} / \mathrm{s}$ powder feed rate. Sample A with images a, c, e, \& $\mathrm{g}$ have the scanning speed of $8 \mathrm{~m} / \mathrm{s}$; while sample $B$ with images $b, d, f, \& h$ has the scanning speed of $10 \mathrm{~m} / \mathrm{s}$. Lower scanning speed indicates a higher concentration of element from powder in the melt, more melt of the substrate, higher temperature-time regime (Günther and Bergmann, 2020). Sample A shows a better grain refinement and a higher percentage of primary VCs precipitations, see Figs. $5 \mathrm{c}$, e \& g, as compared to $d, f \& h$. Sample B shows early precipitation of primary VCs close to the substrate (see Fig. $5 b$, as compared to $5 \mathrm{a}$ ), however, its concentration reduces proportionate as the height of the clad increases, see Figs. $5 d$, f \& h, as compared to c, e \& g. Moreover, this does not have much effect on the hardness of the samples. Sample A has a hardness of $835 \mathrm{HV}$, while B has $776 \mathrm{HV}$, these are much better when compare with the hardness of the substrate which is less than $200 \mathrm{HV}$.

The effect of the laser power on the clad microstructure was also investigated, see Fig. 6.

Figure 6 comprise of two samples, A ( Fig. 6b, d \& f) and C ( Fig. 6a, c \& e). Sample A is fully saturated with carbide of bigger grains compare to sample B. It is observed that lowering laser power from $1200 \mathrm{~W}$ to $800 \mathrm{~W}$ results in the precipitation of primary VCs of smaller grain diameters. The hardness of sample $\mathrm{C}$ is observed to be $778 \mathrm{HV}$.

\section{Discussion}

\subsection{Microstructural characteristics of FeCrV15}

From the micrograph, a round-molded VCs was observed, (Fig. 7 position 2), this begins its precipitation at $2656{ }^{\circ} \mathrm{C}$ (Baker and Okamoto, 1992). VCs precipitate homogeneously at the carbon content of 2.73.15 wt.\% and Vanadium content of 8.15-10.2 wt.\% (Wei et al., 2005), however, it was recently discovered that its precipitation begins at V-content of $₫ 6 \mathrm{wt}$.\% (Günther and Bergmann, 2020). This agrees with the present study. The solidification of the melt results in the precipitation of eutectic vanadium carbides. As indicated by (Baker and Okamoto, 1992), the estimated formation temperature for eutectic vanadium carbides is $1650^{\circ} \mathrm{C}$. Thus, the agglomeration of eutectic VCs in a star-like precipitate forms a heterogeneous core. Just at the temperature below the separatrix line, Cr-rich carbides start to precipitates, Fig. 5 position 5 .

The matrix of the clad comprises of retained austenite and martensite, Fig. 7 (Position $3 \& 4$ ) because a segment in the matrix retained metastable austenite. Filipovic et al. (2009) explained that this situation is because of the high carbon content of FeCrV15, which reduces the martensitic inception temperature, $M_{s}$ to a temperature lower than room temperature. The martensitic zone encapsulating the formed carbides, lowering C-content adjacent to the carbide in the iron-based matrix. Consequently, reduction in C-content leads to an increase of martensitic inception temperature, $M_{s}$. This is the justification for the special arrangement of martensite encapsulating the precipitated carbide, see Figs. 4b, and 5c. 


\subsection{Effect of laser power and scanning speed on microstructural}

Borle et al, Günther and Bergmann stressed that the dilution rate of the melt during weld affect the formation of carbides in the microstructure of the samples(Borle et al., 2015, Günther and Bergmann, 2020). From this experiment, it was observed that close to the substrate, and at an appropriate

temperature(scanning speed) (Lee and Lee, 1992, Baker and Okamoto, 1992), there was enough melt pool from the substrate sufficient enough for the formed carbide(VCs \& Cr-rich) from the melted powder to disolve fully into the matrix as eutectic carbide. This does not give room for the agglomeration of eutectic carbides to form primary carbide, see sample A, Fig. 5a. However, as the distance into the clad increases, there was a remelt of the eutectic carbide-rich layers in addition to the melt of the additional powder, resulting in a high concentration of eutectic carbide which began to agglomerate into star-like primary carbide; this formation increases in size as you move further into the clad, sample A, Fig. 5c, e, f, \& h.

However, at increased scanning speed, there was a reduction in the temperature-time regime, which leads to a reduction in the volume of melt pool from the substrate (i.e., 'reduced dilution rate'). This results in a higher concentration of eutectic VCs leading to the formation of star-like primary VCs precipitate close to the substrate, sample B, Fig. 5b. Moreover, as the distance into the clad increases, the percentage concentration of primary VCs is lower in comparison to sample A, Fig. 5d, f \& h.

Moreover, the reduction of laser power results in the precipitation of smaller grains of primary VCs throughout the microstructure. Lower power results in lower bulk temperature on both the substrate and the powder, which might not be up to the required temperature for primary VCs of bigger grains (Baker and Okamoto, 1992) to precipitate.

\section{Conclusion}

This experiment reaffirms the need for optimization of laser parameters in order to increase the concentration of carbide formation in the microstructure of the clad. Although the dilution rate is minimal in laser cladding, the temperature-time regime has a great impact on the size and formation of primary carbide, its grain refinement, and the modification of the microstructural features due to the reduced or increased thermal impact of alloying elements promoting heterogeneous nucleation. This has a high improvement on the hardness behavior of the samples as compares to the substrate.

These observed differences would be further study to see the impact of changes in the macrostructure of the clad relatively to its height on the abrasive wear.

\section{Declarations}

\section{Declaration of Competing Interest}


The authors declare that there is no known contending monetary interests or individual connections that might have had influence on this work.

\section{Acknowledgment}

The authors acknowledge the support from Tshwane University of Technology (TUT), Pretoria, South Africa, without which this work would not have been possible.

\section{References}

1. ARAMIDE, B. P., POPOOLA, A. P. I., SADIKU, E. R., ARAMIDE, F. O., JAMIRU, T. \& PITYANA, S. L. 2020. Wear-Resistant Metals and Composites. In: KHARISSOVA, O. V., MARTÍNEZ, L. M. T. \& KHARISOV, B. I. (eds.) Handbook of Nanomaterials and Nanocomposites for Energy and Environmental Applications. Cham: Springer International Publishing.

2. BAKER, H. \& OKAMOTO, H. 1992. Alloy phase diagrams, ASM handbook. ASM International, 3, 501.

3. BAYER, R. G. 2008. Wear Analysis for Engineers. Industrial Lubrication and Tribology, 60.

4. BORLE, S. D., LE GALL, I. \& MENDEZ, P. F. 2015. Primary chromium carbide fraction control with variable polarity SAW. Weld. J, 94, 1-7.

5. BOUAIFI, B., BARTZSCH, J., GEBERT, A. \& HEINZE, H. 1997. UNTERSUCHUNGEN ZUM PLASMAAUFTRAGSCHWEISSEN VON VERSCHLEISSFESTEN HARTSTOFFSCHICHTEN MIT VANADIUMCARBIDEN. Schweissen + Schneiden.

6. FILIPOVIC, M., ROMHANJI, E., KAMBEROVIC, Z. \& KORAC, M. 2009. Matrix microstructure and its micro-analysis of constituent phases in as-cast Fe-Cr-CV alloys. Materials transactions, 50, 24882492.

7. GÜNTHER, K. \& BERGMANN, J. P. 2020. Influencing Microstructure of Vanadium Carbide Reinforced FeCrVC Hardfacing during Gas Metal Arc Welding. Metals, 10, 1345.

8. LAMPMAN, J. \& PETERS, A. 1981. Ferroalloys and other additives to liquid iron and steel, ASTM International.

9. LEE, B.-J. \& LEE, D. N. 1992. A thermodynamic evaluation of the Fe-Cr-VC system. Journal of phase equilibria, 13, 349-364.

10. MA, S.-F., LIANG, J., ZHAO, J.-F. \& XU, B.-S. 2010. Synthesis, characterization and growth mechanism of flower-like vanadium carbide hierarchical nanocrystals. CrystEngComm, 12, 750-754.

11. TOYSERKANI, E., KHAJEPOUR, A. \& CORBIN, S. F. 2004. Laser cladding, CRC press.

12. WEI, S., ZHU, J. \& XU, L. 2005. Research on wear resistance of high speed steel with high vanadium content. Materials Science and Engineering: A, 404, 138-145.

\section{Figures}




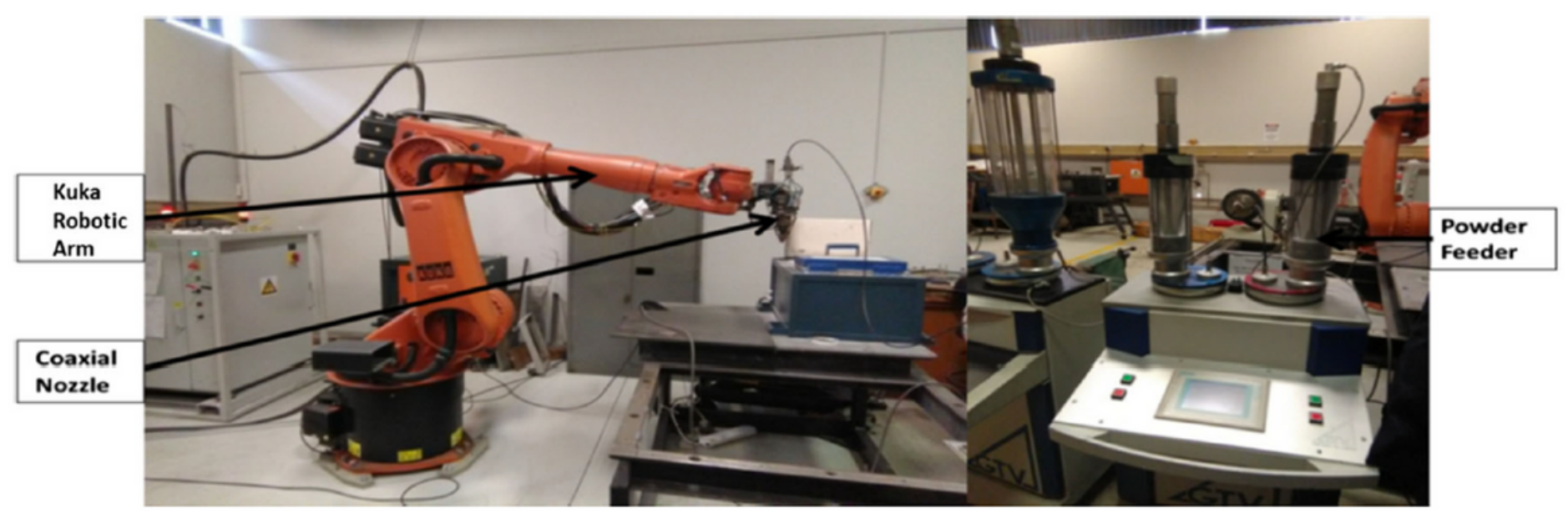

Figure 1

Continuous Wave(CW) Rofin Sinar Nd:YAG laser system
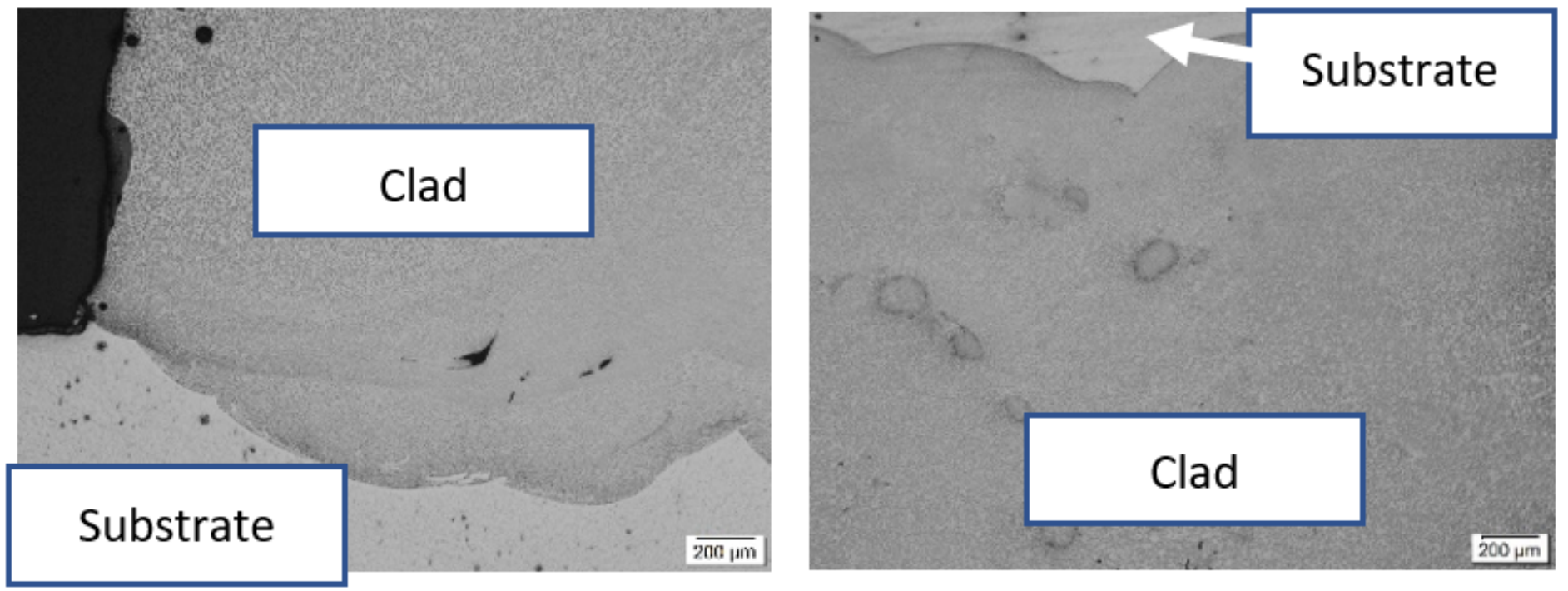

Figure 2

Sample A and C after the cladding. 

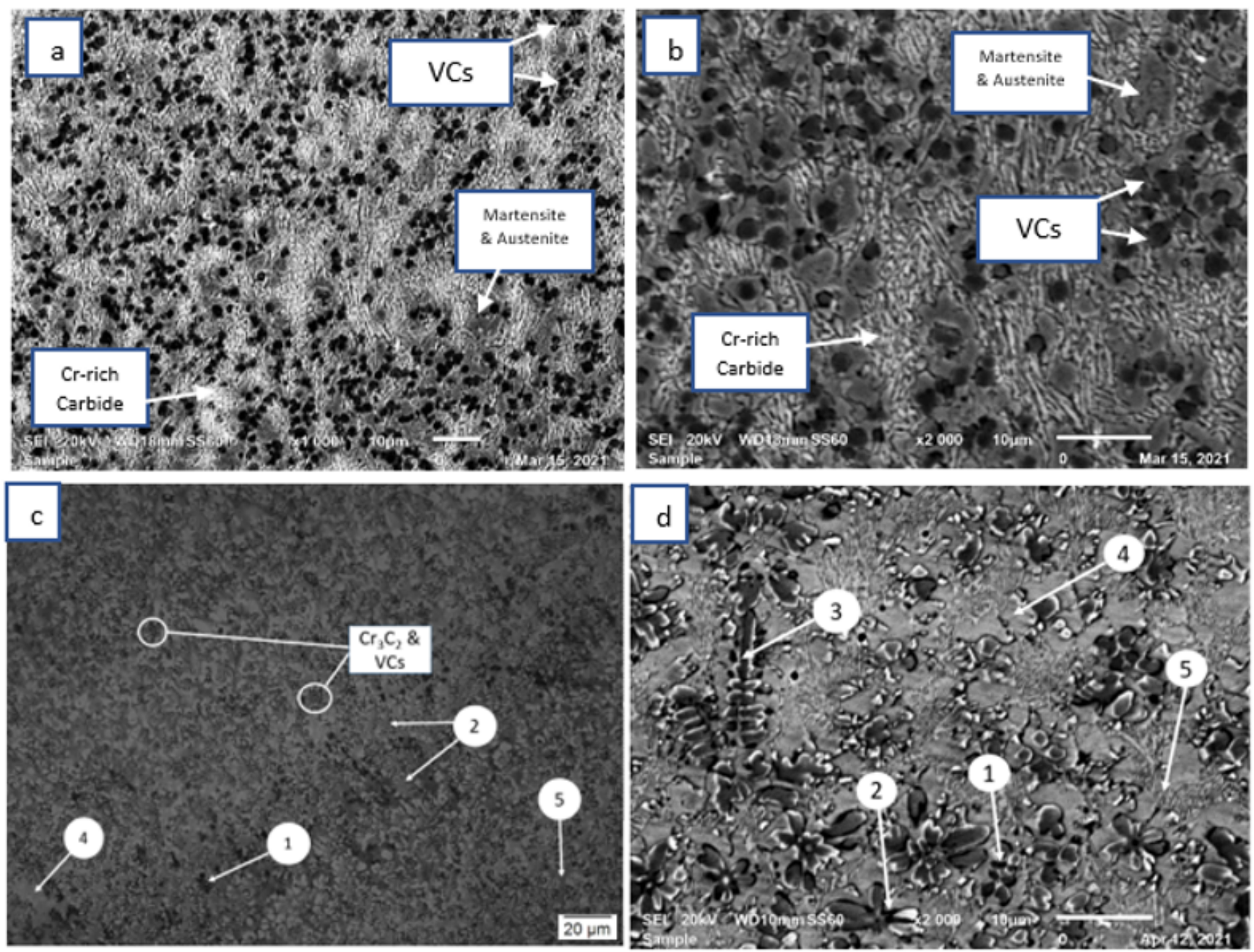

(1) Eutectic VCs $2 \& 3$ Primary VCs

(4)

Martensite \& Austenite

(5)

Cr-rich Carbide

\section{Figure 3}

The image of the microstructure 

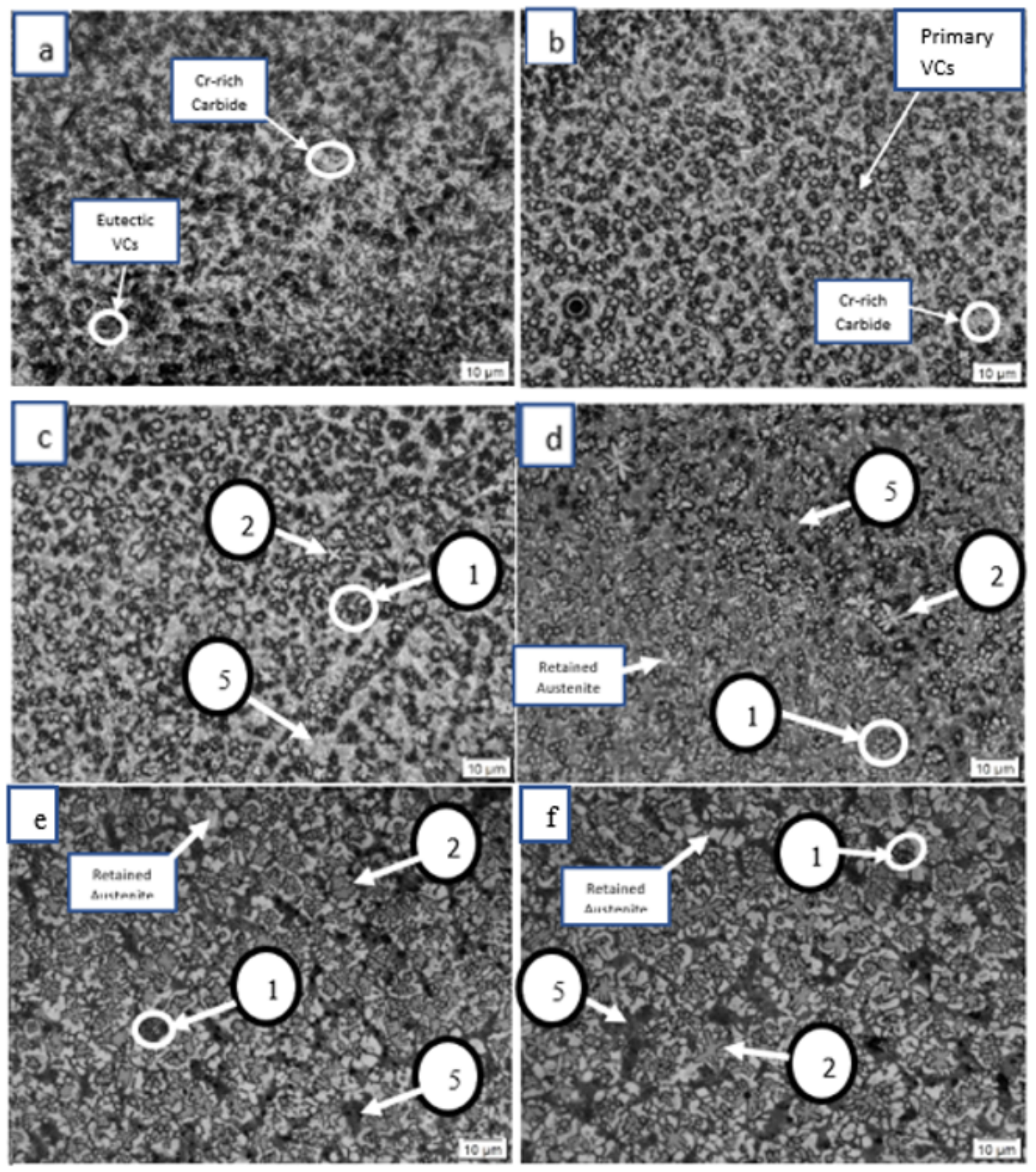

\section{(1) Eutectic VCs (2) Primary VCs (5) Cr-rich carbide}

Figure 4

Agglomeration of eutectic VCs forming star-like primary VCs. 

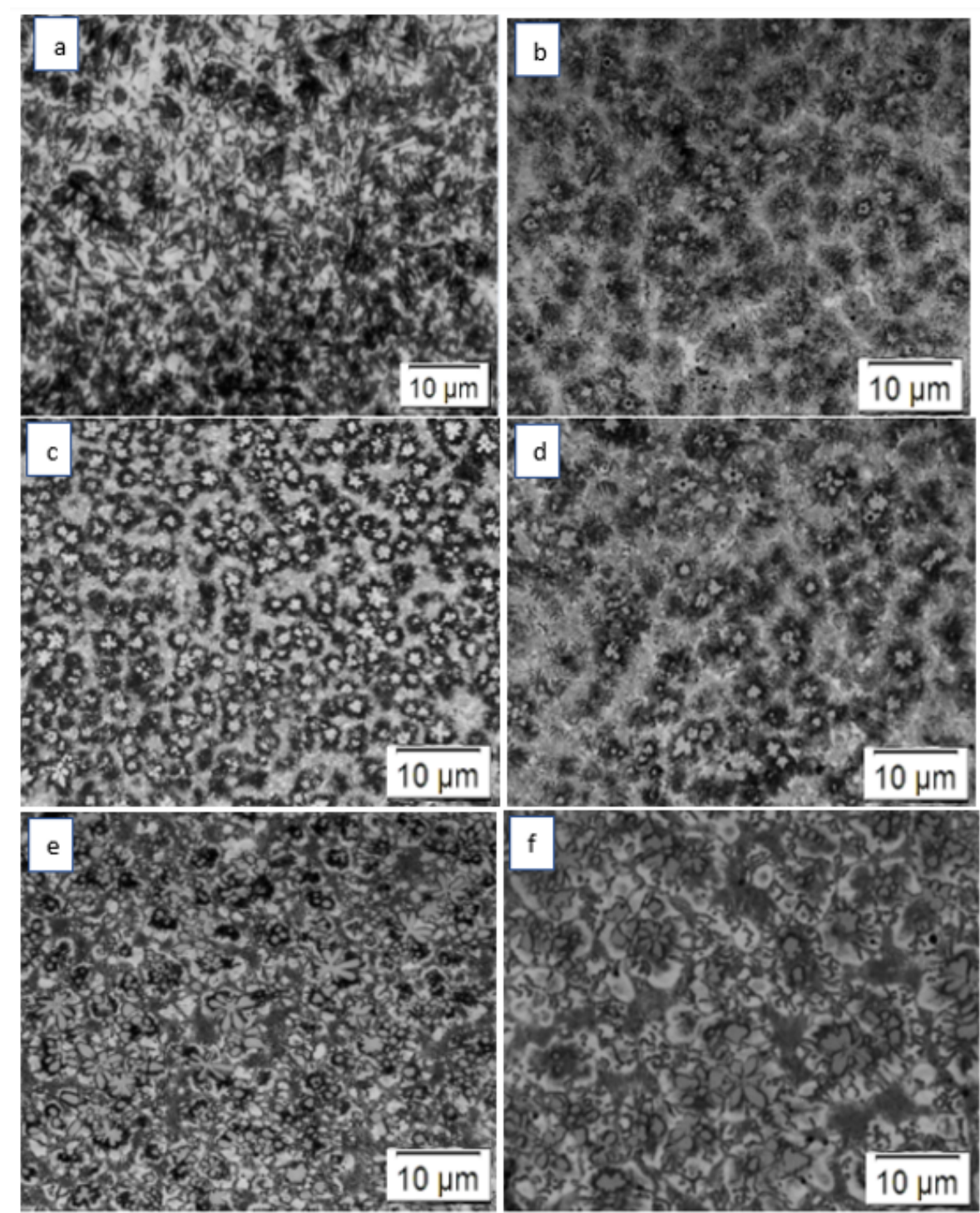

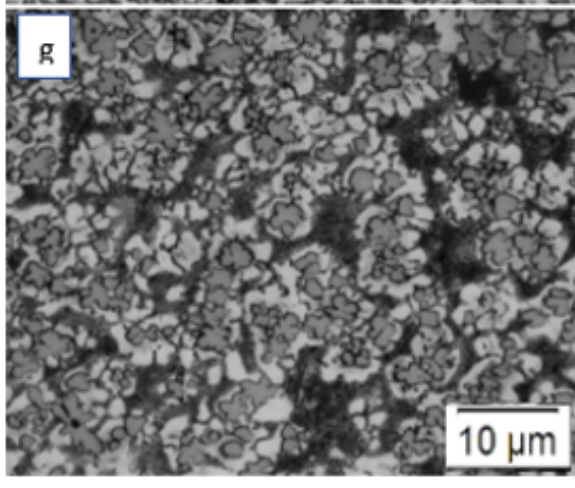

Sample A

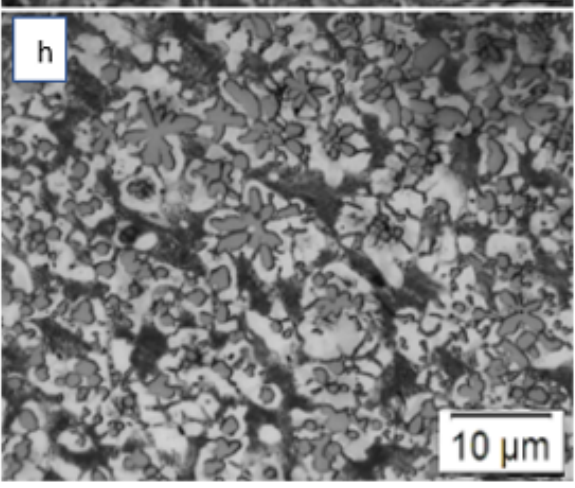

Sample C

\section{Figure 5}

Influence of scanning speed on the microstructure of the clad 

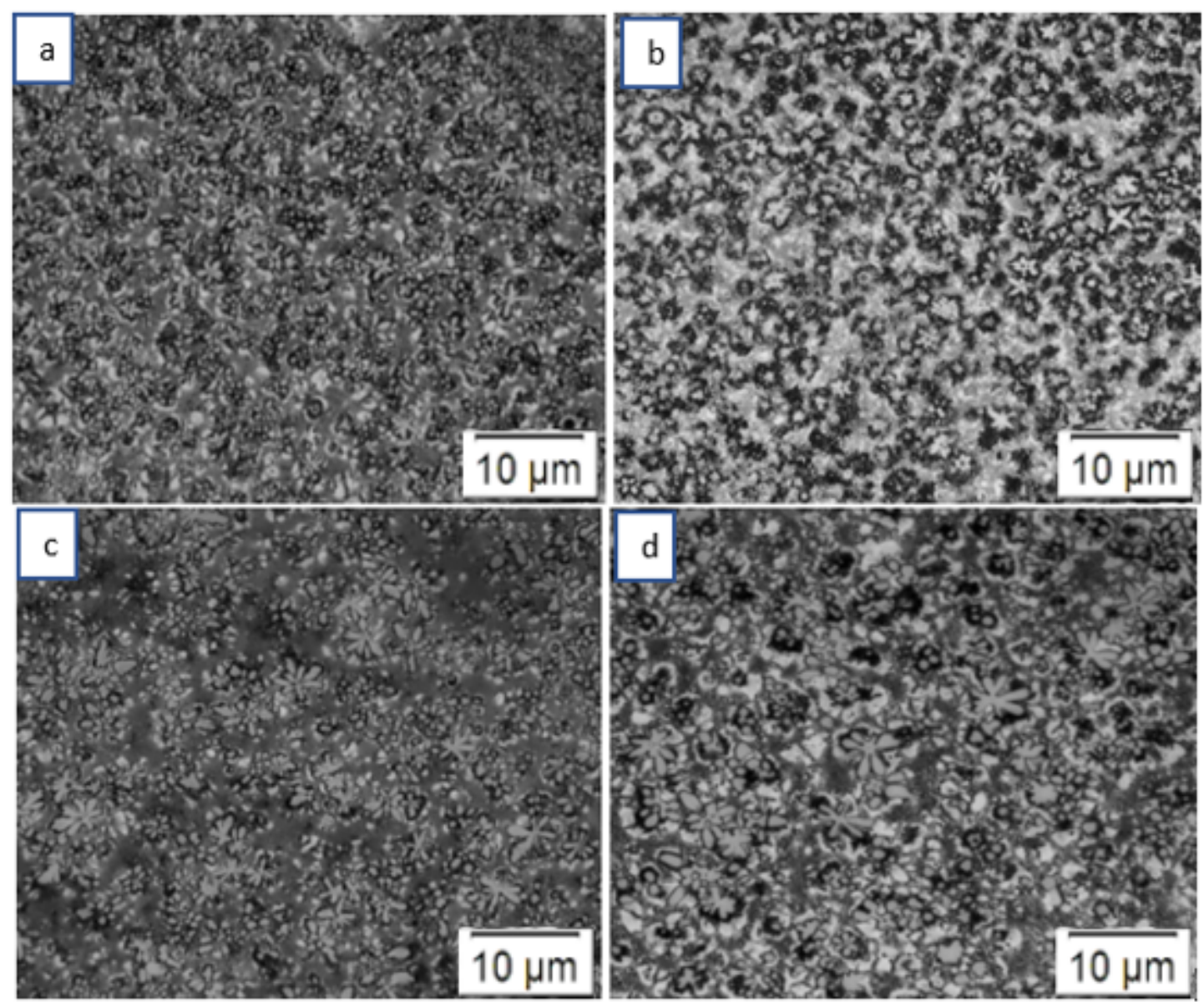

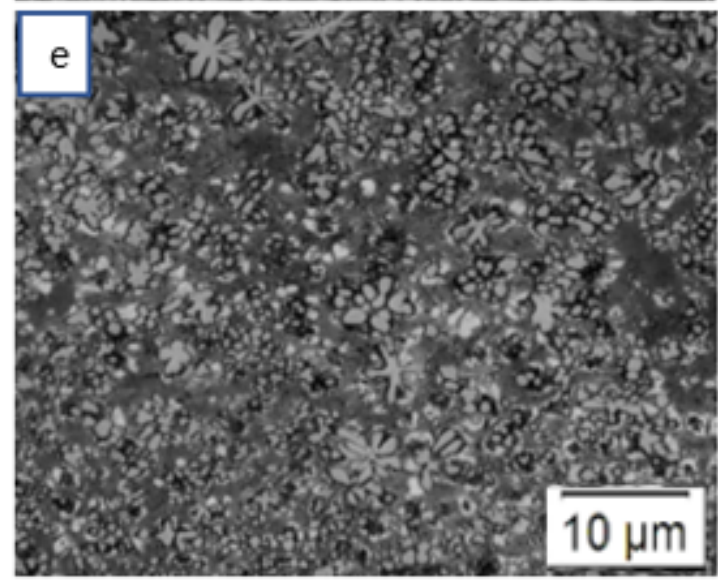

Sample B

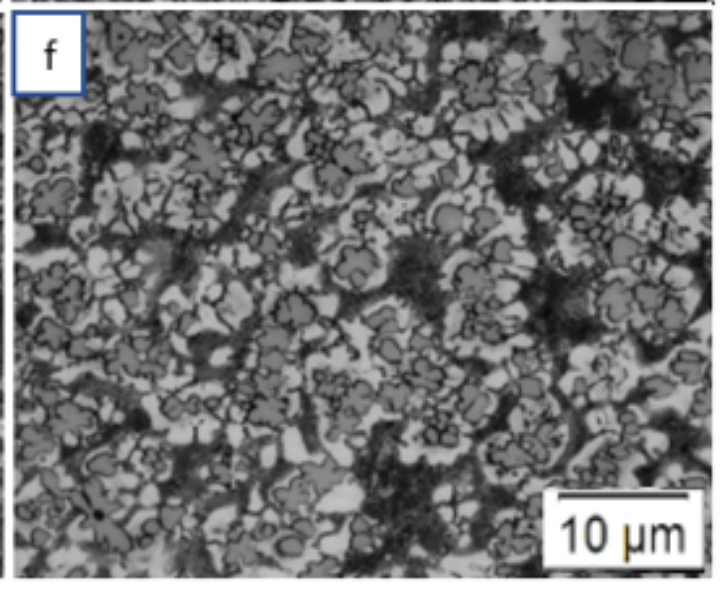

Sample A

\section{Figure 6}

Influence of laser power on the microstructure of the clad 


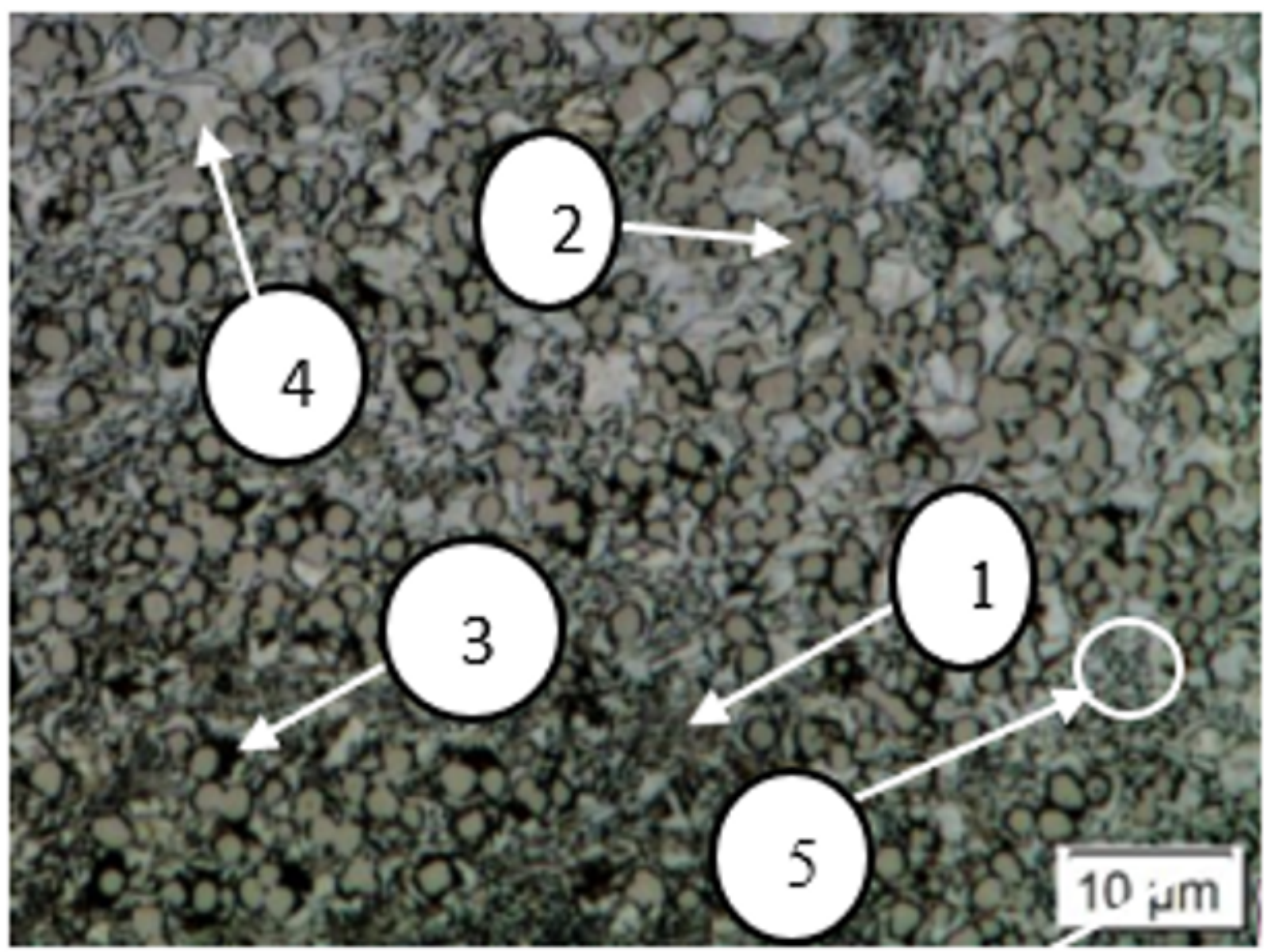

Figure 7

Round-shaped Vanadium Carbide 